Waste and Resource Management Volume 169 Issue WR3

High-value resource recovery products from waste tyres

Zhang, Wu, Nahil and Williams

ice | proceedings

\title{
High-value resource recovery products from waste tyres
}

Yeshui Zhang BSC, MSC

Research Student, School of Chemical and Process Engineering, University of Leeds, Leeds, UK

Chunfei wu BSC, MSc, PhD, MRSC

Research Fellow, Department of Chemical Engineering, University of Hull, Hull, UK

\author{
Mohamad A. Nahil BEng, PhD \\ Research Fellow, School of Chemical and Process Engineering, University of \\ Leeds, Leeds, UK \\ Paul Williams BSC, MSC, PhD, CEng, FEl, MCIWM \\ Professor, School of Chemical and Process Engineering, University of Leeds, \\ Leeds, UK (corresponding author: p.t.williams@leeds.ac.uk)
}

A novel process has been developed which enables the production of high-value carbon nanotubes (CNTs) and hydrogen-rich syngas from the two-stage pyrolysis-catalysis of waste tyres. The waste tyre samples originated from truck tyres and from car tyres. In addition, three of the main rubber elastomers used in tyre manufacture, polybutadiene rubber, styrene-butadiene rubber and natural rubber, were also investigated. The waste car tyres produced a syngas yield of $\mathbf{3 0 . 2} \mathbf{w t} \%$, which was composed largely of hydrogen $\mathbf{( 5 3 . 8}$ vol\%) with a calorific value of $18.8 \mathrm{MJ} / \mathrm{m}^{3}$. Increasing the tyre:catalyst ratio increased the yield of hydrogen. The component rubber elastomers produced much higher yields of syngas and hydrogen gas concentration. The carbon deposited on the catalyst during reaction was found to be mostly composed of graphitic CNTs. Changing the process conditions in terms of tyre:catalyst ratio could increase the yield of the carbon deposited on the catalyst to up to $14 \mathrm{wt} \%$.

\section{Introduction}

The treatment and disposal of waste tyres represent a major waste management issue with an estimated 1.5 billion endof-life tyres generated annually worldwide (ETRMA, 2011). The management of waste tyres is a major problem in Europe, with more than $3 \mathrm{Mt}$ of waste tyres generated annually (ETRMA, 2013) and with an estimated stockpile of $5.7 \mathrm{Mt}$ throughout Europe (Williams, 2013). The treatment of waste tyres in Europe is mostly through their use as an alternative fuel for energy recovery in cement kilns (35 wt $\%$ ), material recovery by way of sports fields and playgrounds (33 wt $\%$ ) in civil engineering applications such as embankments and foundation material $(7 \mathrm{wt} \%)$, tyre retreading $(8 \mathrm{wt} \%)$ and by export (10 wt \%) (Williams, 2013).

There is significant resource invested in tyre manufacture, including fossil fuel petroleum for synthetic rubber manufacture and for the production of carbon black for filler material. For example, it has been estimated that a new passenger car tyre can contain the equivalent of $\sim 30$ litres of petroleum oil and heavy duty tyres contain an oil equivalent of $\sim 93$ litres (ETRMA, 2013). With heightened concern in relation to sustainability and resource recovery, there is a growing interest in alternative technologies that can recover valuable products from tyres rather than from tyre combustion and low-grade uses (Sienkiewicz et al., 2012). Sienkiewicz et al. (2012) have comprehensively reviewed the progress of waste tyre management in Europe and highlighted the considerable potential of pyrolysis as an alternative treatment option for waste tyres.

Pyrolysis has been investigated as a process route to degrade waste tyres thermally. At a typical pyrolysis temperature of $\sim 500^{\circ} \mathrm{C}$ and in an inert atmosphere, the tyre rubber is decomposed to produce solid carbon, liquid oil and gaseous products (Sienkiewicz et al., 2012; Williams, 2013). The gaseous products are typically hydrogen $\left(\mathrm{H}_{2}\right)$ and $\mathrm{C}_{1}-\mathrm{C}_{4}$ hydrocarbons with high calorific value (CV) and can be used as process fuel; the oil product can be used directly as a fuel with characteristics similar to gas oils and the solid char product can be used as solid fuel or low-grade carbon black. In more advanced systems, pyrolysis can be coupled with catalysts to upgrade the oils to premium grade fuels or chemicals or to produce hydrogen (Williams, 2013).

There is particular interest in the production of hydrogen since it is regarded as a clean energy carrier that only generates water on combustion and features as a major energy resource in potential future energy scenarios. Two-stage pyrolysiscatalysis reactors have been used to enhance hydrogen production from waste tyres with the catalyst having been used to improve the efficiency of hydrogen production. For example, Elbaba and Williams (2013) and Elbaba et al. (2011) investigated several nickel-based catalysts to improve the production 
of hydrogen for the pyrolysis-catalysis steam reforming of waste tyres. Nickel $(\mathrm{Ni})$ catalysts are commonly used for hydrogen production. However, nickel-based catalysts become deactivated due to the deposition of carbonaceous coke on the catalyst surface, adversely influencing hydrogen production (Sehested, 2006; Sutton et al., 2001; Yung et al., 2009). There are three main types of carbon deposited on the catalyst, pyrolytic carbon, encapsulating amorphous carbon and whiskertype carbon (Rostrup-Nielsen, 1975; Sehested, 2006). It is the amorphous carbons that primarily deactivate the catalyst by encapsulating the active metal sites of the catalyst. The whiskertype carbons are solid and filamentous in nature but in some cases hollow carbon nanotubes (CNTs) have been identified (Wu et al., 2013). CNTs comprise a tubular material composed of a graphitic hexagonal carbon structure with diameters ranging from 1 to $50 \mathrm{~nm}$ and lengths ranging from several microns to several centimetres. The current interest in CNTs is due to their unique physical and chemical characteristics, which have been demonstrated to have great potential in several materials industries, such as advanced electronics, carbon composites and energy storage (Volder et al., 2013). They are regarded as high-value materials, with single-wall nanotubes generally of much higher value than multi-walled CNTs. Therefore, the problem of coke formation on the catalyst during hydrogen production may, in fact, be an advantage if CNTs can be produced in addition to the co-production of hydrogen. Additionally, using waste tyres as feedstock for the process means that a problematic waste is turned into an attractive process solution by producing valuable CNTs and hydrogen as resource recovered products.

In this paper, the authors report on the pyrolysis-catalysis of waste tyres with the aim of determining the yield and composition of products such as syngas, with an emphasis on hydrogen production and also on the production of multiwalled CNTs. Waste truck tyres and car tyres were used as the feedstock and the catalyst used was an nickel-alumina $\left(\mathrm{Al}_{2} \mathrm{O}_{3}\right)$ catalyst. In addition, the production of hydrogen and CNTs from some of the main rubbers used in tyre manufacture was also investigated to better understand the process.

\section{Materials and methods}

\subsection{Materials}

The waste tyre samples used in the experiments were waste truck tyres and waste car tyres with the metal and reinforcing fabric removed and the rubber then shredded to a particle size of $\sim 6 \mathrm{~mm}$. A typical tyre may contain $\sim 46 \mathrm{wt} \%$ rubber, $\sim 22 \mathrm{wt} \%$ carbon black filler/strengthener, $\sim 19 \mathrm{wt} \%$ of metal reinforcement and a balance of textile reinforcement, sulfur, zinc and other additives (Evans and Evans, 2006). In addition, three rubber elastomers commonly used in tyre manufacture were also investigated, such as polybutadiene rubber (BR),

\begin{tabular}{lcrrrr} 
Components: wt\% & Truck tyre & Car tyre & BR & SBR & NR \\
\hline Carbon & $81 \cdot 2$ & 81.7 & 87.4 & 87.0 & 86.3 \\
Hydrogen & $7 \cdot 2$ & 6.5 & $10 \cdot 7$ & 9.9 & 11.2 \\
Nitrogen & 0.8 & 0.6 & nd & nd & nd \\
Sulfur & $2 \cdot 1$ & 1.9 & nd & nd & nd
\end{tabular}

nd, not detected

Table 1. Elemental analysis of truck tyre, car tyre, BR, SBR and NR

styrene-butadiene rubber (SBR) and natural rubber (NR), which were shredded to the same particle size as the waste tyres. The elemental analysis of the different tyres and rubbers is shown in Table 1. The thermal decomposition characteristics of the tyres and rubbers were determined on a Shimadzu thermogravimetric analyser (TGA), where the tyre/rubber $(15 \mathrm{mg})$ was heated from room temperature to $800^{\circ} \mathrm{C}$ at $10^{\circ} \mathrm{C} / \mathrm{min}$ for a hold time of 10 min under an nitrogen $\left(\mathrm{N}_{2}\right)$ atmosphere. The weight loss of the sample as a function of temperature is recorded continuously.

The nickel/alumina catalyst was prepared by the wetness impregnation method. Nickel was impregnated onto an alumina support to produce $10 \mathrm{wt} \%$ of metal with the alumina support. The catalyst preparation process involved the following: nickel nitrate was dissolved in ethanol; alumina was added to the mixture of nickel nitrate/ethanol to produce a slurry; the slurry was dried at $90^{\circ} \mathrm{C}$; calcination at $750^{\circ} \mathrm{C}$ in air; crushing and sieving to produce a $0 \cdot 05-0 \cdot 18 \mathrm{~mm}$ particle size range.

\subsection{Experimental system}

The tyre pyrolysis-catalysis experiments were conducted in a two-stage fixed-bed reactor consisting of two separate stainless steel reactors that were externally electrically heated (Figure 1). Pyrolysis of the tyres and rubbers $(1 \mathrm{~g})$ took place in the first stage reactor at pyrolysis heating conditions of ambient temperature to $600^{\circ} \mathrm{C}$ at $40^{\circ} \mathrm{C} / \mathrm{min}$ heating rate and held at $600^{\circ} \mathrm{C}$ for $20 \mathrm{~min}$. The volatiles from tyre/rubber pyrolysis passed to the second stage reactor which contained the nickel-alumina catalyst $(0.5 \mathrm{~g})$, which was maintained at $800^{\circ} \mathrm{C}$. The tyre: catalyst ratio was therefore $1: 0 \cdot 5$. In addition, other experiments were undertaken to determine the influence of increasing the amount of catalyst in the second-stage reactor at tyre: catalyst ratios of 1:1 and 1:2. The two-stage reactor was continually purged with nitrogen to maintain pyrolytic conditions and to carry the product gases into the condensation system. The condensation of condensable liquids was by water and dry ice condensers. Gases passing through the condensers were collected in a 25 litres Tedlar gas sample bag for later analysis. 


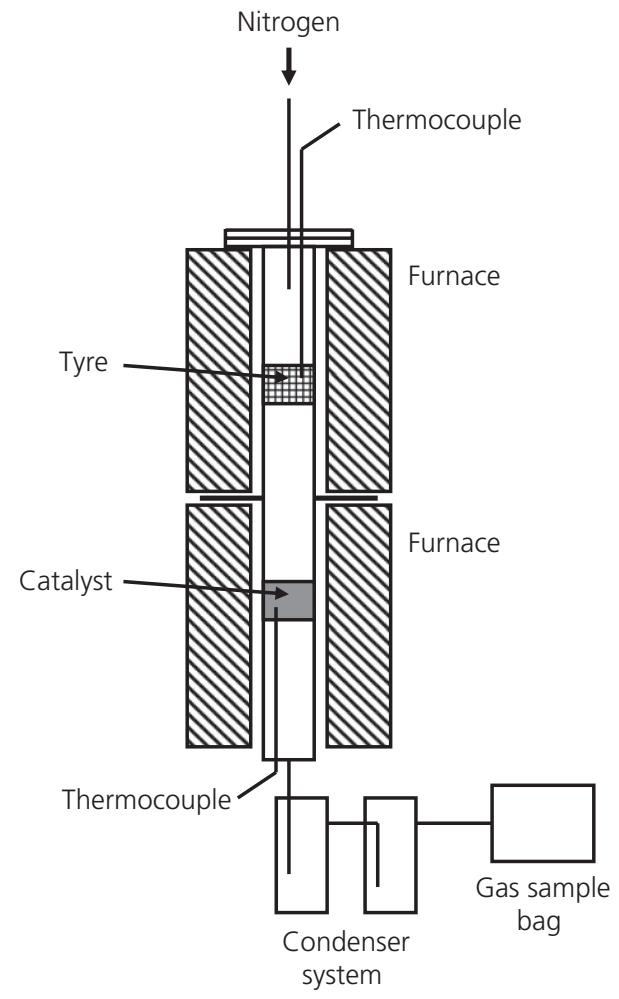

Figure 1. Schematic diagram of the two-stage fixed-bed pyrolysis-catalytic reactor system

Experiments were repeated to ensure the accuracy of the results.

\subsection{Analytical methods}

The gases collected in the Tedlar gas sample bag were analysed using gas chromatography. The permanent gases (hydrogen, carbon monoxide (CO), oxygen and nitrogen) were determined on a Varian 3380 gas chromatograph (GC) with a 60-100 mesh molecular sieve $13 \mathrm{X}$ column, using argon as the carrier gas and a thermal conductivity detector. Carbon dioxide was analysed on the same Varian GC but with a separate 80-100 mesh HayeSep column and thermal conductivity detector. Hydrocarbons from $\mathrm{C}_{2}-\mathrm{C}_{4}$ were analysed using a second Varian 3380 GC with a HayeSep 80-100 mesh molecular sieve column, nitrogen as the carrier gas and flame ionisation detector.

The carbon deposition, including the amorphous, pyrolytic, filamentous and CNTs deposited on the nickel-alumina catalyst, was characterised through temperature-programmed oxidation (TPO) using a Shimadzu TGA. After the reaction $\sim 4 \mathrm{mg}$ of the catalyst was heated to $800^{\circ} \mathrm{C}$ at a heating rate of $15^{\circ} \mathrm{C} / \mathrm{min}$ in air. In addition, the deposited carbon on the catalyst surface was examined using an Hitachi SU8230 scanning electron microscope (SEM) and a Fellow of the Energy Institute (FEI) Tecnai TF20 transmission electron microscope (TEM). A Renishaw Invia Raman spectroscopy with a wavelength of $514 \mathrm{~nm}$ at Raman shifts between 100 and $3200 \mathrm{~cm}^{-1}$ was used to obtain the Raman analysis results, which were used to indicate the graphitic nature of the carbon.

\section{Results and discussion}

\subsection{Characterisation of the feedstock rubber samples}

The thermal degradation of waste tyres and rubber samples was characterised using thermogravimetric analysis. Figure 2 shows the resultant thermograms and shows that the main decomposition for NR occurs at a peak temperature of $385^{\circ} \mathrm{C}$, for SBR, the main decomposition peaks at $460^{\circ} \mathrm{C}$ and for BR at a temperature of $475^{\circ} \mathrm{C}$. The three rubbers also showed a much smaller weight loss at higher temperatures for the NR and at lower temperatures for the SBR and BR. Kandasamy and Gökalp (2015) reported slightly different maximum thermal degradation temperatures of 375,445 and $465^{\circ} \mathrm{C}$ for $\mathrm{NR}$, SBR and BR, respectively, probably due to minor differences in their compositions. Figure 2 also shows the TGA thermograms for waste car tyres and truck tyres, which indicate two decomposition peak temperatures. The data suggest that the lower temperature weight loss peak at a temperature of $385^{\circ} \mathrm{C}$ may be ascribed to the thermal decomposition of NR and the higher weight loss temperature peaking at $\sim 430^{\circ} \mathrm{C}$ may be ascribed to the thermal decomposition of SBR and BR. However, the interpretation of weight loss is more complicated, since a typical automotive tyre can be composed of up to 30 different synthetic rubbers and eight different kinds of NRs (Evans and Evans, 2006). Sulkowski et al. (2004) have also suggested that the two temperature weight loss regimes for waste tyres are due to the thermal decomposition of the different rubber components in tyres. In addition, Seidelt et al. (2006) have reported the presence of a third weight loss peak at lower temperatures which they attributed to the volatilisation of the additives used in tyre manufacture, including hydrocarbon oils, moisture, plasticisers and other additives.

\subsection{Product yield from pyrolysis-catalysis of tyres and rubbers}

Pyrolysis-catalysis of the waste car tyres, truck tyres and the tyre rubber samples in the presence of the nickel/alumina catalyst was carried out in the two-stage reactor system and the results for product yield and gas composition are shown in Table 2. The comparison of car tyres and truck tyres at a tyre: catalyst ratio of 1:0.5 showed small differences in product yield; for example, the gas yields from the pyrolysis-catalysis of car tyres were $30 \cdot 2$ and $27 \cdot 5 \mathrm{wt} \%$ for truck tyres. Moreover, 


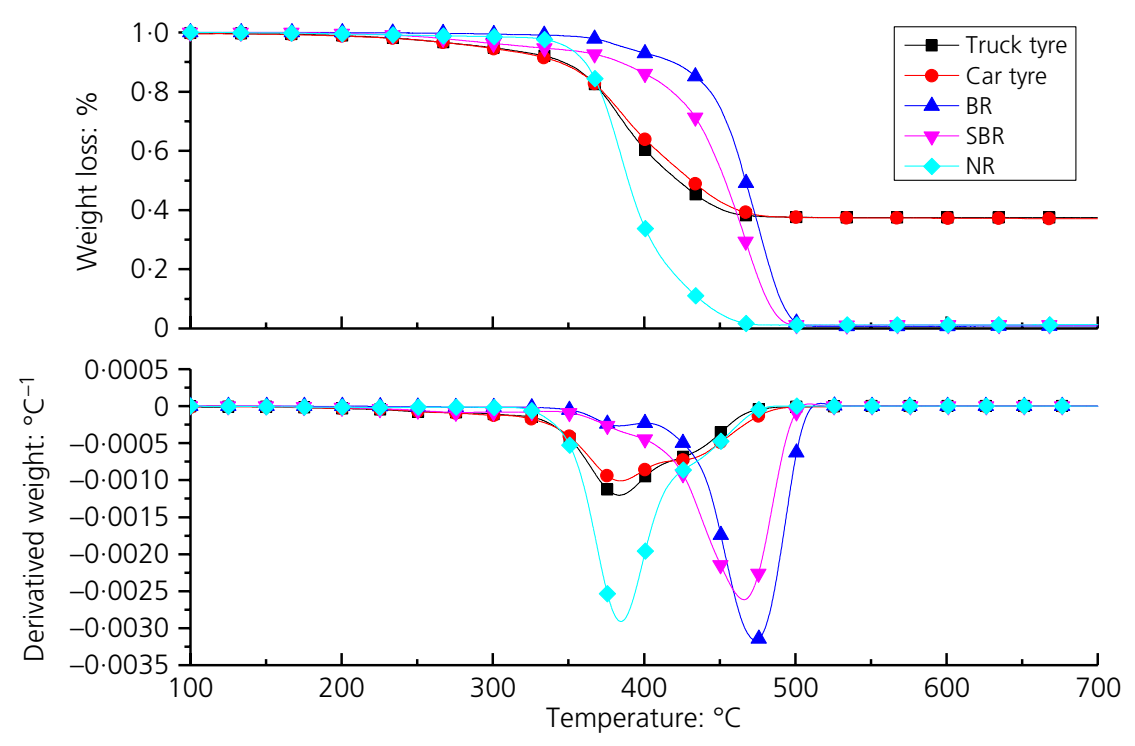

Figure 2. TGA and DTG analysis results of the feedstock truck tyre, car tyre, BR, SBR and NR

\begin{tabular}{|c|c|c|c|c|c|c|c|}
\hline Feedstock & Truck tyre & Truck tyre & Truck tyre & Car tyre & $\mathrm{BR}$ & SBR & NR \\
\hline Tyre:catalyst ratio & $1: 0 \cdot 5$ & $1: 1$ & $1: 2$ & $1: 0 \cdot 5$ & $1: 0 \cdot 5$ & $1: 0 \cdot 5$ & $1: 0 \cdot 5$ \\
\hline \multicolumn{8}{|l|}{ Product yield } \\
\hline Gas yield: wt\% & $27 \cdot 5$ & $29 \cdot 7$ & $29 \cdot 5$ & $30 \cdot 2$ & $41 \cdot 3$ & $39 \cdot 3$ & $52 \cdot 8$ \\
\hline Liquid yield: wt\% & $22 \cdot 0$ & $12 \cdot 0$ & $14 \cdot 0$ & $21 \cdot 0$ & $23 \cdot 0$ & $17 \cdot 0$ & $17 \cdot 0$ \\
\hline Char residue: wt\% & $37 \cdot 0$ & $38 \cdot 0$ & $38 \cdot 0$ & $40 \cdot 0$ & $2 \cdot 0$ & $1 \cdot 0$ & 0.0 \\
\hline Carbon deposits: wt\% & $8 \cdot 0$ & $14 \cdot 0$ & $13 \cdot 0$ & $3 \cdot 0$ & $36 \cdot 0$ & $40 \cdot 0$ & $36 \cdot 0$ \\
\hline Hydrogen production: mmol/g tyre/rubber & $11 \cdot 0$ & $16 \cdot 7$ & $21 \cdot 8$ & $12 \cdot 0$ & $16 \cdot 3$ & $16 \cdot 8$ & $25 \cdot 0$ \\
\hline \multicolumn{8}{|l|}{ Gas concentrations: vol\% } \\
\hline Carbon monoxide & $19 \cdot 4$ & $16 \cdot 0$ & $18 \cdot 9$ & $27 \cdot 1$ & $4 \cdot 8$ & $4 \cdot 6$ & $8 \cdot 9$ \\
\hline Hydrogen & $49 \cdot 6$ & $60 \cdot 0$ & $68 \cdot 3$ & $53 \cdot 8$ & $46 \cdot 8$ & $47 \cdot 1$ & $51 \cdot 8$ \\
\hline Methane & $23 \cdot 4$ & $15 \cdot 7$ & $9 \cdot 4$ & $5 \cdot 8$ & $35 \cdot 4$ & $40 \cdot 6$ & $31 \cdot 8$ \\
\hline Carbon dioxide & $0 \cdot 0$ & 0.0 & $0 \cdot 0$ & $0 \cdot 0$ & $0 \cdot 2$ & $0 \cdot 2$ & 0.5 \\
\hline $\mathrm{C}_{2}-\mathrm{C}_{4}$ & $5 \cdot 9$ & $6 \cdot 4$ & $3 \cdot 4$ & $10 \cdot 7$ & $7 \cdot 6$ & $6 \cdot 2$ & $5 \cdot 3$ \\
\hline Calorific value: $\mathrm{MJ} / \mathrm{m}^{3}$ & $20 \cdot 9$ & $19 \cdot 3$ & $16 \cdot 4$ & $18 \cdot 8$ & $24 \cdot 4$ & $25 \cdot 5$ & $22 \cdot 8$ \\
\hline
\end{tabular}

Table 2. Product yield and gas concentrations from the pyrolysis-catalysis of truck tyre, car tyre, BR, SBR and NR

the char residue left in the pyrolysis reactor after the reaction differed, producing $40 \mathrm{wt} \%$ for waste car tyres and $37 \mathrm{wt} \%$ for waste truck tyres. These differences were most probably due to the different rubbers and formulations used to produce the tyres. The residual char is produced from polymerisation reactions of the evolved high molecular weight hydrocarbon species during pyrolysis, and also from the carbon black added to the tyre which, as discussed before, can be typically $22 \mathrm{wt} \%$ of the tyre (Evans and Evans, 2006). Of more significance was the difference between the two tyre samples in terms of the carbon deposition, which represented carbon deposited mainly on the catalyst and also some on the walls of the catalytic reactor. For the truck tyre, this was $8 \mathrm{wt} \%$, but for the car tyre was $3 \mathrm{wt} \%$, again, probably representing different formulations of each tyre sample which influenced the pyrolysis-catalysis process. Table 2 also shows the influence of increasing the 
tyre:catalyst ratio on the product yield, with larger amounts of catalyst producing greater conversion of the tyre rubber to carbon deposits, rising from $8.0 \mathrm{wt} \%$ at $1: 0.5$ tyre:catalyst ratio to $13 \cdot 0-14 \cdot 0 \mathrm{wt} \%$ at higher ratios.

An analysis of the gas composition (Table 2) showed that the gas product from the pyrolysis-catalysis of waste tyres was mainly carbon monoxide, hydrogen and methane. The hydrogen content of the product gas was high, producing $49 \cdot 6 \mathrm{vol} \%$ for the waste truck tyre and $53.8 \mathrm{vol} \%$ for the waste car tyre. The hydrogen yield in terms of the mass of tyre rubber was similar for the two tyres at $11 \cdot 0-12.0 \mathrm{mmol} / \mathrm{g}$ tyre. Increasing the amount of catalyst relative to the amount of tyre resulted in a large increase in hydrogen production from $11.0 \mathrm{mmol} / \mathrm{g}$ tyre at a tyre:catalyst ratio of $1: 0.5$ to $21.8 \mathrm{mmol} / \mathrm{g}$ tyre at a tyre:catalyst ratio of $1: 2$. The hydrogen concentration in the product gas correspondingly increased to $68.3 \mathrm{vol} \%$. Table 2 also shows the calculated $\mathrm{CV}$ of the product gases. The $\mathrm{CV}$ of the gases produced from the tyres was between 16.4 and $20.9 \mathrm{MJ} / \mathrm{m}^{3}$, depending on the process conditions, which is sufficient to provide the energy requirements for the pyrolysiscatalysis process. Considering also that the total gas yield was between 27.5 and $30.2 \mathrm{wt} \%$ of tyre, the gas could also be exported off-site for use as fuel gas.

Pyrolysis-catalysis of the three rubber samples is also presented in Table 2 where the product yields show a much higher conversion of the rubbers to gas and carbon deposits on the catalyst, with low residual char formation in the first-stage reactor compared with the yields from waste tyres. The highest gas yield was from NR at $52.8 \mathrm{wt} \%$ and was largely composed of hydrogen and methane, giving a rubber conversion to hydrogen of $25.0 \mathrm{mmol} / \mathrm{g}$ of NR. The total gas yields from the two synthetic rubbers (BR and SBR) were much lower at $\sim 40 \mathrm{wt} \%$ and lower hydrogen yield in terms of mass of rubber at $\sim 16.5 \mathrm{mmol} / \mathrm{g}$ rubber compared with the tyre results. The carbon deposits formed on the catalysts from the pyrolysiscatalysis of the three rubber samples were very high compared with the tyre feedstock at 36, 40 and $36 \mathrm{wt} \%$ for BR, SBR and $\mathrm{NR}$, respectively.

Overall, the pyrolysis-catalysis of waste tyres has shown a high conversion of the tyre rubber to gas which is largely composed of hydrogen, methane and carbon monoxide, producing a product gas with a high $\mathrm{CV}$ of between 16.4 and $20.9 \mathrm{MJ} / \mathrm{m}^{3}$ depending on the type of tyre and the tyre:catalyst ratio. All the three rubber samples investigated, BR, SBR and NR, have a major contribution to the total gas yield and the hydrogen yield. The product gas can be used as process fuel and/or exported off-site. Alternatively, hydrogen could be separated and used in high-purity hydrogen applications such as fuel cells and hydrogen-fuelled engines to fuel the predicted future hydrogen economy.
The three rubber samples produced a major contribution to carbon deposits on the catalyst at between 36 and $40 \mathrm{wt} \%$. Consequently, the individual rubber formulation in the tyre strongly influences the amount of carbon deposition on the catalyst during the pyrolysis-catalysis process. Normally high formation of coke on the catalyst is deemed as a major problem to the catalytic process since the active metal sites of the catalyst become blocked and hence the catalyst becomes deactivated. However, as discussed above, the more problematic carbons which coke the catalyst surface are the amorphous encapsulating type. Therefore, a detailed characterisation of the coke deposits formed on the catalyst during pyrolysiscatalysis of the waste tyres and rubber samples with the nickel/ alumina catalyst was carried out. Figure 3 shows the TPO results for the carbon deposits on the catalysts used with waste car tyres, waste truck tyres, and the BR, SBR and NR. During the oxidation process, the weight loss of the catalyst/carbon is recorded as the different types of carbon (amorphous or graphitic) are oxidised as the temperature of the TGA is raised. Figure 3 shows that the main weight loss of the reacted catalysts resulting from carbon oxidation occurred between temperatures of 450 and $600^{\circ} \mathrm{C}$ and was assigned to the oxidation of amorphous carbon. The oxidation that occurred after a temperature of $600^{\circ} \mathrm{C}$ was assigned to the oxidation of filamentous/whisker-type carbon (Wu and Williams, 2010; Wu et al., 2013).

\subsection{Carbon formation}

Table 2 shows that carbon formation on the catalyst (coke deposits) for the catalyst used in the pyrolysis-catalysis of waste tyre samples was significant, being up to $14 \mathrm{wt} \%$ depending on the process conditions.

Figure 3 indicates that the used catalysts for waste car tyres and waste truck tyres display one peak representing the oxidation of the coke deposited on the catalyst, whereas the catalysts used with BR, SBR and NR have two temperature peaks representing carbon oxidation. The oxidation peak of the coke deposits on the catalyst for the car tyre pyrolysis-catalysis occurred at a lower temperature $\left(585^{\circ} \mathrm{C}\right)$ compared with the oxidation of the coke deposits on the catalyst from the waste truck tyre $\left(615^{\circ} \mathrm{C}\right)$, suggesting that the coke deposits were a mixture of amorphous and graphitic-type carbons, but amorphous dominating for the car tyre and more graphitic filamentous carbons produced with the truck tyre reaction. The TPO thermograms for the rubber samples show that BR and SBR show two temperature peaks, but the largest is at the lower temperature range, below $600^{\circ} \mathrm{C}$ indicating a dominance of amorphous carbon, but significant graphitic-type carbons also occurred indicated by carbon oxidation at around $650^{\circ} \mathrm{C}$. In contrast, the NR sample produced mainly graphitic carbons (oxidising at $\sim 650^{\circ} \mathrm{C}$ ) and less amorphous carbon (oxidising at $580^{\circ} \mathrm{C}$ ). The proportions of 

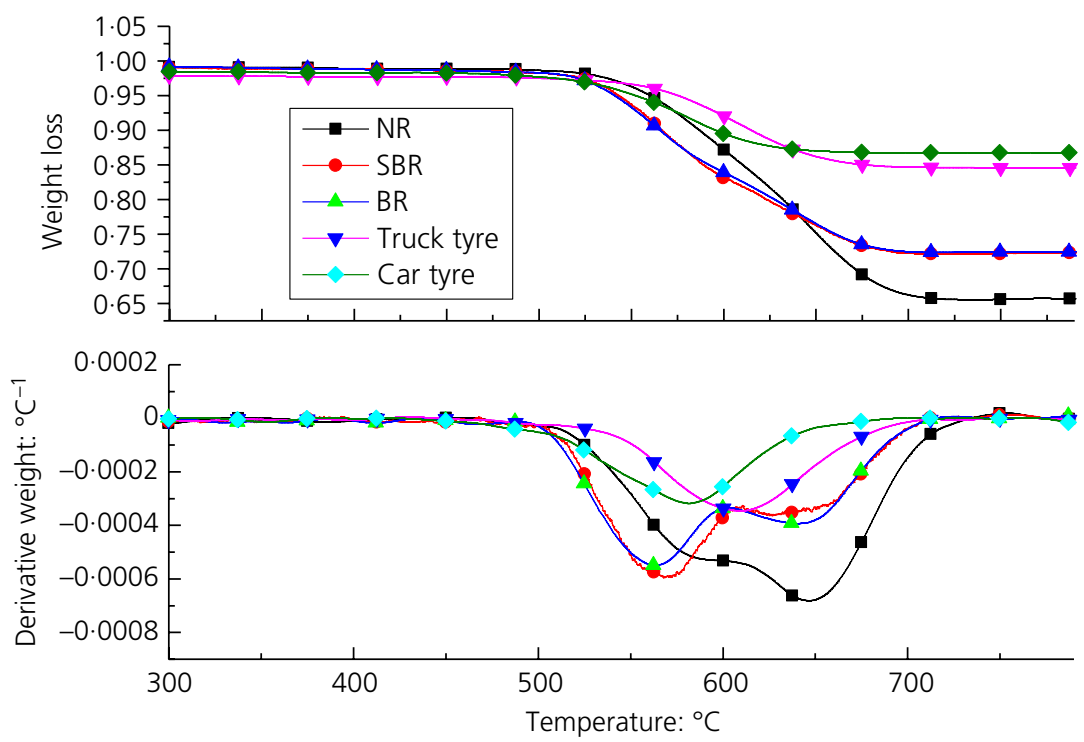

Figure 3. TGA-TPO and DTG-TPO results of the used catalysts

from the pyrolysis-catalysis of truck tyre, car tyre, BR, SBR and NR

amorphous and graphitic-type carbons have been estimated from the TPO thermograms shown in Figure 3 and the results are shown in Figure 4. Figure 4 indicates that much higher yields of catalyst carbon are produced from the pyrolysis-catalysis of the three rubber samples. The amorphous carbons comprised between 164 and $196 \mathrm{mg}$ carbon/g rubber and the graphitic carbons a higher proportion comprising between 196 and $204 \mathrm{mg}$ carbon/g rubber. The waste tyre samples produced much lower deposition of carbon on the catalysts during reaction, with the truck tyre generating higher carbon deposition compared with the car tyre. Increasing the amount of catalyst resulted in a higher carbon deposition per mass of tyre, for example, the truck tyre produced $44 \mathrm{mg}$ of graphitic carbon/g tyre at a tyre:catalyst ratio of 1:0.5, which increased to $78 \mathrm{mg}$ of graphitic carbon/g tyre at a tyre:catalyst ratio of 1:2. Therefore, the graphitic carbon represents $54 \%$ of the carbon present on the catalyst at a tyre: catalyst ratio of $1: 0 \cdot 5$, rising to $60 \%$ at a tyre:catalyst ratio of $1: 2$.

The deposits of carbon (coke) formed on the nickel/alumina catalyst during pyrolysis-catalysis of the tyres/rubbers were examined using scanning electron microscopy and transmission electron microscopy (Figure 5). The coke deposited on the catalyst produced from the pyrolysis-catalysis of the three rubber samples all show the presence of filamentous or whisker-type carbons (Sehested, 2006). These appear as entangled string-like filaments of $\sim 10 \mathrm{~nm}$ diameter and several microns in length. An examination of the TEM micrographs shows that the vast majority of these filamentous carbons are in fact hollow nanosized filaments - that is, CNTs. Figure 5 also shows that the carbon deposited on the catalyst used for pyrolysis-catalysis of

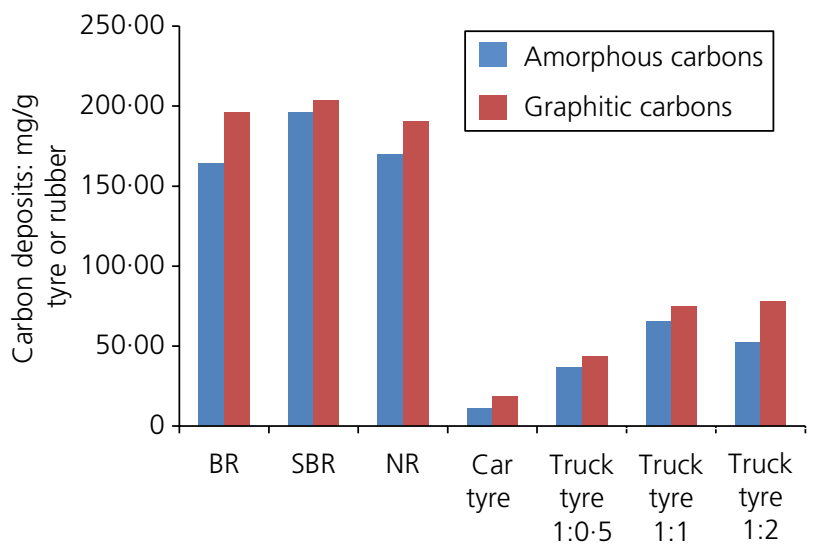

Tyre and rubber type

Figure 4. Proportion of amorphous and graphitic-type carbons formed from the pyrolysis-catalysis of truck tyre, car tyre, BR, SBR and NR

truck tyres also shows this entangled nanotube structure. However, the car tyre showed a poorer development of CNTs, as also shown in Figures 3 and 4 where a more amorphous type of catalyst carbon deposition was indicated. Most probably this is due to the particular rubber and additive formulation of the car tyre compared with the truck tyre. CNTs have several different structures, including for example, straight, coiled, waved, branched and entangled CNTs (Karthikeyan and Mahalingam, 2013; Sears et al., 2010; Zhang and Li, 
Waste and Resource Management Volume 169 Issue WR3
High-value resource recovery products

from waste tyres

Zhang, Wu, Nahil and Williams

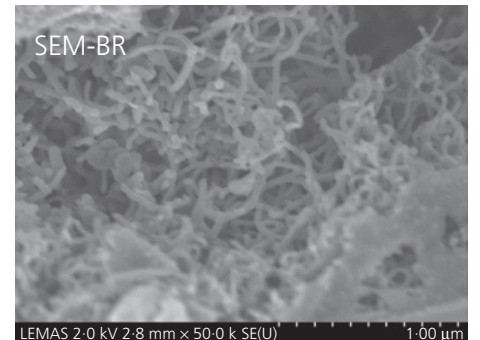

(a)

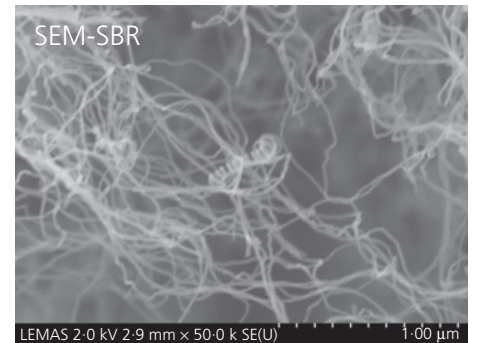

(c)

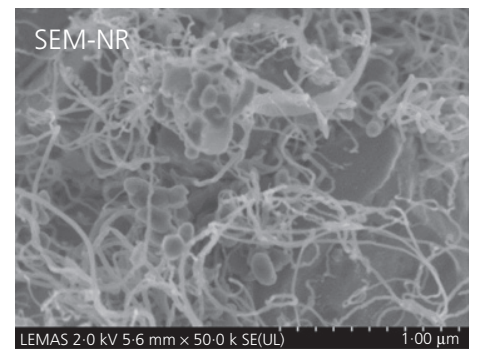

(e)

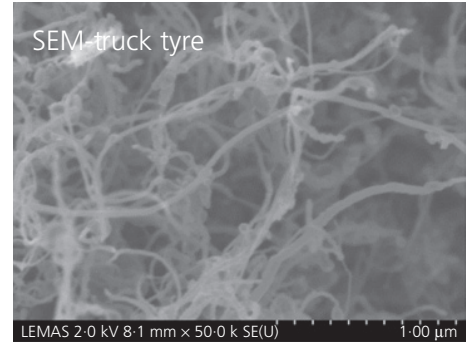

(g)

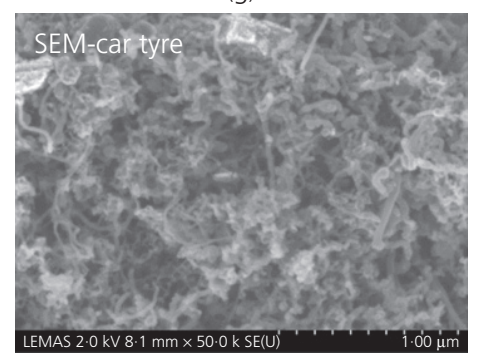

(i)

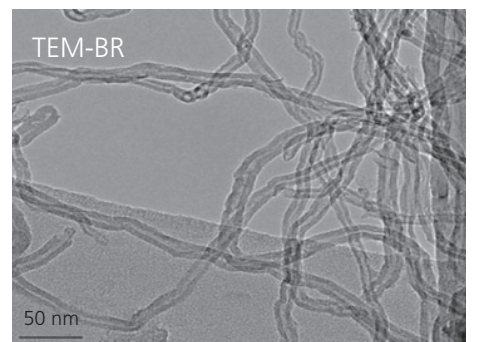

(b)

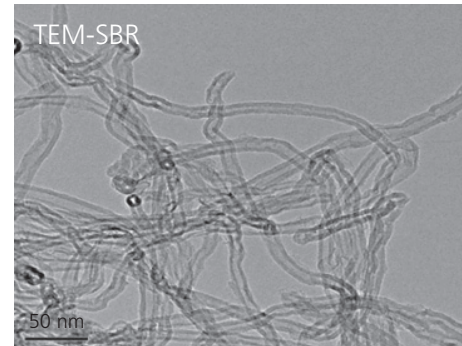

(d)

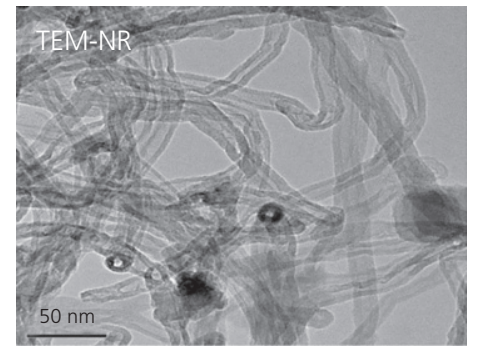

(f)

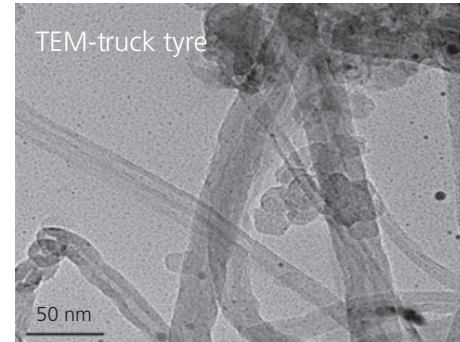

(h)

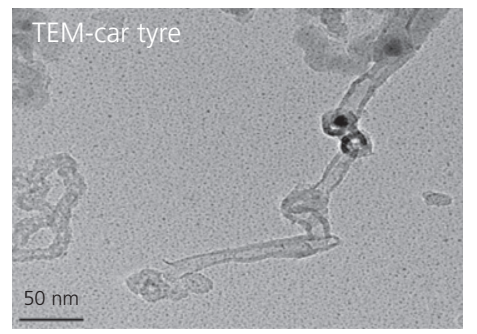

(j)

Figure 5. SEM and TEM images of e carbon deposited on the catalyst from the pyrolysis-catalysis of truck tyre, car tyre, BR, SBR and NR 


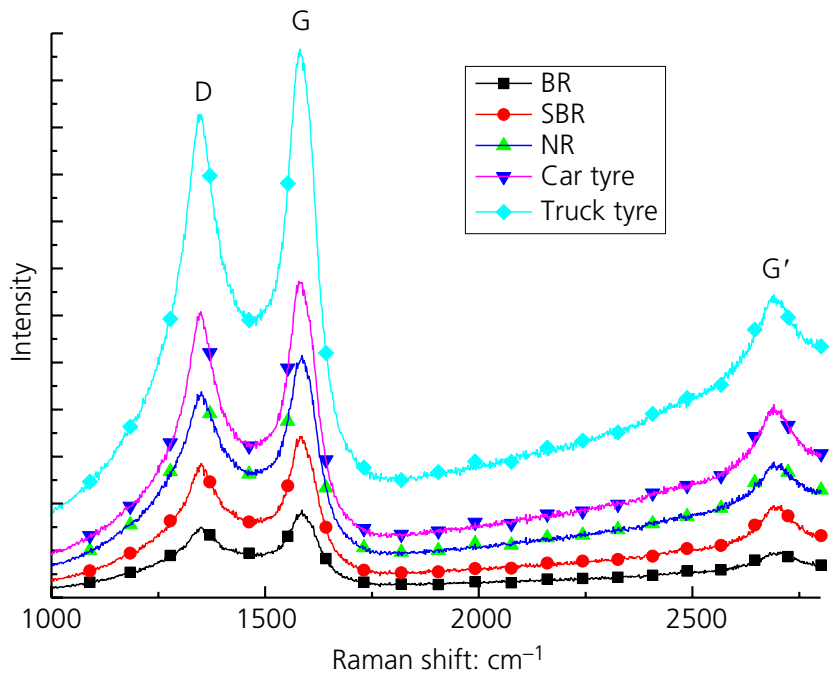

Figure 6. Raman analysis of the carbon deposited on the catalyst from the pyrolysis-catalysis of truck tyre, car tyre, BR, SBR and NR

2009). Entangled CNTs as shown in Figure 5 have been proposed for use in water and air purification applications (Karthikeyan and Mahalingam, 2013; Sears et al., 2010). In relation to the TPO results shown in Figure 3, Li et al. (2004) have also suggested that the weight loss in relation to carbon oxidation at temperatures $<600^{\circ} \mathrm{C}$ may also be due to oxidation of single-walled CNTs as they are less thermally stable compared with multi-walled CNTs, stability arising from the strong interaction between graphite layers in multi-walled CNTs. The TEM micrographs of carbon deposited onto the catalyst during the reaction, presented in Figure 5, show that there are CNTs with different diameters, where thinner walled CNTs may be thermally less stable than thicker walled nanotubes.

Raman spectroscopy is commonly used to determine the quality of CNTs and Raman spectroscopy analysis was used to further characterise the quality of CNTs. The results are shown in Figure 6. The two main spectral peaks for the carbon deposits occur at $\sim 1580$ and $1350 \mathrm{~cm}^{-1}$. The $\sim 1580 \mathrm{~cm}^{-1}$ peak is designated as the $G$ peak and represents the resonance peak of graphitic carbon indicating a well-crystallised carbon structure and the peak at $\sim 1350 \mathrm{~cm}^{-1}$ designated as the D peak is the scattering peak of disordered carbon indicating defects in the graphitic crystalline structure or amorphous carbon (Karthikeyan and Mahalingam, 2013; Yang et al., 2010). The intensity $(I)$ of each peak and the ratio of the two peak intensities $I_{\mathrm{D}} / I_{\mathrm{G}}$ are used to determine the degree of crystallisation of the carbon structure, with a higher $I_{\mathrm{D}} / I_{\mathrm{G}}$ ratio indicating higher quality in regard to CNTs. A G' peak is also obtained at Raman shifts of around $2709 \mathrm{~cm}^{-1}$ and is a further indication of
CNT purity. The intensity of the $\mathrm{D}$ band $\left(I_{\mathrm{D}}\right)$ normalised to the intensity of the $\mathrm{G}$ band $\left(I_{\mathrm{G}}\right)\left(I_{\mathrm{D}} / I_{\mathrm{G}}\right)$ and intensity ratio of $\mathrm{G}^{\prime}$ to $\mathrm{G}\left(I_{\mathrm{G}^{\prime}} / I_{\mathrm{G}}\right)$ was used to evaluate the quality of CNTs. The $I_{\mathrm{D}} / I_{\mathrm{G}}$ and $I_{\mathrm{G}^{\prime}} / I_{\mathrm{G}}$ values for the carbons produced with $\mathrm{NR}, \mathrm{BR}$ and SBR showed no significant differences being $0.83 \pm 0.01$ for the $I_{\mathrm{D}} / I_{\mathrm{G}}$ values and $0.54 \pm 0.02$ for the $I_{\mathrm{G}^{\prime}} / I_{\mathrm{G}}$ values. The Raman spectra for the carbon derived from waste tyres were similar to each other with a small increase in both $I_{\mathrm{D}} / I_{\mathrm{G}}$ and $I_{\mathrm{G}^{\prime}} / I_{\mathrm{G}}$ values at $0.89 \pm 0.01$ and $0.57 \pm 0.02$, respectively. The data confirm that the carbons deposited on the catalyst during the pyrolysiscatalysis of waste tyres and rubber samples contained both amorphous and CNTs, which is also indicated by the TGA results (Figure 3) and TEM micrographs (Figure 5).

\section{Conclusions}

The pyrolysis-catalysis of waste car tyres and truck tyres has been investigated using an nickel/alumina catalyst to investigate its suitability for the production of a hydrogen-rich syngas and also CNTs. In addition, the results were compared with the production of hydrogen and CNTs from the three main rubbers used in the manufacture of automotive tyres. The main conclusions were as follows.

- The yield of gas obtained from the pyrolysis-catalysis of the waste car tyre was $30 \cdot 2 \mathrm{wt} \%$. The gas was composed of $53.8 \mathrm{vol} \%$ of hydrogen with the other main gases being carbon monoxide and methane, giving a product gas with a CV of $18.8 \mathrm{MJ} / \mathrm{m}^{3}$. The conversion of the tyre rubber to hydrogen was $12 \cdot 0 \mathrm{mmol}$ hydrogen/g tyre. The pyrolysiscatalysis of the waste truck tyre produced slightly lower yields of gas $(27 \cdot 5 \mathrm{wt} \%)$, lower hydrogen gas concentration $(49.6 \mathrm{vol} \%)$ and lower conversion of the tyre rubber to hydrogen (11.0 mmol hydrogen/g tyre).

- Increasing the tyre:catalyst ratio for the waste truck tyres was found to improve the conversion of the tyre rubber to hydrogen to $21.8 \mathrm{mmol}$ hydrogen $/ \mathrm{g}^{1}$ tyre at a tyre:catalyst ratio of $1: 2$, which produced a hydrogen concentration in the product gas of $68 \cdot 3 \mathrm{vol} \%$.

- For the three rubber samples, product gas yields and conversion of the rubber to hydrogen were much higher than was the case with the waste tyres; for example, NR produced the largest gas yield at $52 \cdot 8 \mathrm{wt} \%$ of rubber feedstock and the highest conversion to hydrogen, yielding $25.0 \mathrm{mmol}$ hydrogen $/ \mathrm{g}^{1}$ rubber.

- The pyrolysis-catalysis process also produced significant deposition of carbon onto the catalyst. Examination of the carbon using transmission electron microscopy supported by TPO and Raman spectroscopy showed that the carbons produced from the waste tyres and the rubber samples were CNTs of diameters between 5 and $10 \mathrm{~nm}$ and lengths of several microns. For the waste tyres, the maximum deposition of carbon was found at $\sim 14 \mathrm{wt} \%$ of 
tyre (tyre:catalyst ratio 1:1). However, for the rubber samples, BR, SBR and NR, the carbon deposition on the catalyst was 36,40 and $36 \mathrm{wt} \%$, respectively.

- The process of pyrolysis-catalysis of waste tyres has the potential to provide a novel alternative waste treatment process to produce a hydrogen-rich syngas, which can be used as process fuel or with the option to be upgraded to high-purity hydrogen gas for the projected future hydrogen economy. In addition, the process produces carbon deposits on the catalyst which comprise mostly CNTs which have the potential to be further processed to produce a highvalue product to support the advanced materials industry.

\section{REFERENCES}

Elbaba IF and Williams PT (2013) High yield hydrogen from the pyrolysis-catalytic gasification of waste tyres with a nickel/dolomite catalyst. Fuel 106: 528-536.

Elbaba IF, Wu C and Williams PT (2011) Hydrogen production from the pyrolysis-gasification of waste tyres with a nickel/cerium catalyst. International Journal of Hydrogen Energy 36(11): 6628-6637.

ETRMA (European Tyre and Rubber Manufactureres' Association) (2011) ELT Management. ETRMA, Saint-Josse-ten-Noode, Belgium.

ETRMA (2013) Introduction to Tyre Recycling: 2013 (Twenty Years of Tyre Recycling in the EU). ETRMA, Saint-Josse-ten-Noode, Belgium.

Evans A and Evans R (2006) The Composition of a Tyre: Typical Components. Waste \& Resources Action Programme, Banbury, Oxford, UK.

Kandasamy J and Gökalp I (2015) Pyrolysis, combustion, and steam gasification of various types of scrap tires for energy recovery. Energy and Fuels 29(1): 346-354.

Karthikeyan S and Mahalingam P (2013) Carbon nanotubes from unconventional resources: part A: entangled multi-walled carbon nanotubes and part B: vertically aligned carbon nanotubes, chapter 11. In Synthesis and Applications of Carbon Nanotubes and their Composites (Suzuki S (ed.)). InTech Publishers, Rijeka, Croatia, pp. 239-255.

Li Q, Yan H, Zhang J and Liu Z (2004) Effect of hydrocarbons precursors on the formation of carbon nanotubes in chemical vapor deposition. Carbon 42(4): 829-835.

Rostrup-Nielsen JR (1975) Steam Reforming Catalysts. Danish Technical Press, Copenhagen, Denmark.

Sears K, Dumee L, Schutz J et al. (2010) Recent developments in carbon nanotube membranes for water purification and gas separation. Materials 3: 127-149.

Sehested J (2006) Four challenges for nickel steam-reforming catalysts. Catalysis Today 111(1-2): 103-110.

Seidelt S, Müller-Hagedorn M and Bockhorn H (2006) Description of tire pyrolysis by thermal degradation behaviour of main components. Journal of Analytical and Applied Pyrolysis 75(1): 11-18.

Sienkiewicz M, Kucinska-Lipka J, Janik H and Balas A (2012)

Progress in used tyres management in the European Union: a review. Waste Management 32(10): 1742-1751.

Sulkowski WW, Danch A, Moczynski M et al. (2004)

Thermogravimetric study of rubber waste-polyurethane composites. Journal of Thermal Analysis and Calorimetry 78(3): 905-921.

Sutton D, Kelleher B and Ross JRH (2001) Review of literature on catalysts for biomass gasification. Fuel Processing Technology 73(3): 155-173.

Volder MFLD, Tawfick SH, Baughman RH and Hart AJ (2013) Carbon nanotubes: present and future commercial applications. Science 339(6119): 535-539.

Williams PT (2013) Pyrolysis of waste tyres: a review. Waste Management 33(8): 1714-1728.

Wu C and Williams PT (2010) Pyrolysis-gasification of post-consumer municipal solid plastic waste for hydrogen production. International Journal of Hydrogen Energy 35(3): 949-957.

Wu C, Nahil MA, Miskolczi N, Huang J and Williams PT (2013) Processing real-world waste plastics by pyrolysis-reforming for hydrogen and high-value carbon nanotubes. Environmental Science and Technology 48(1): 819-826.

Yang Z, Zhang Q, Luo G et al. (2010) Coupled process of plastics pyrolysis and chemical vapour deposition for controllable synthesis of vertically aligned carbon nanotube arrays. Applied Physics A: Materials Science and Processing 100: 533-540.

Yung MM, Jablonski WS and Magrini-Bair KA (2009) Review of catalytic conditioning of biomass-derived syngas. Energy and Fuels 23(4): 1874-1887.

Zhang M and Li J (2009) Carbon nanotube in different shapes. Materials Today 12(6): 12-18.

\section{HOW CAN YOU CONTRIBUTE?}

To discuss this paper, please email up to 500 words to the editor at journals@ice.org.uk. Your contribution will be forwarded to the author(s) for a reply and, if considered appropriate by the editorial board, it will be published as discussion in a future issue of the journal.

Proceedings journals rely entirely on contributions from the civil engineering profession (and allied disciplines). Information about how to submit your paper online is available at www.icevirtuallibrary.com/page/authors, where you will also find detailed author guidelines. 